\title{
PSYCHIATRIC CHANGES ASSOCIATED WITH FRIEDREICH'S ATAXIA
}

\author{
BY \\ D. L. DAVIES \\ From the Maudsley Hospital, London
}

The occurrence of mental changes in association with Friedreich's ataxia has received sporadic notice from time to time. Saquet (1919) reviewed the literature on this subject. Further contributions from the neuro-pathological standpoint came from Trelles (1934), whilst the genetics of this association received comment from de Smet and others (1937). Sjögren (1943) and Davies (1949) have discussed the occurrence of dementia in Friedreich's ataxia, whilst Bleuler and Walder (1946) have attempted to clarify Bleuler's concept of "the psycho-organic syndrome" by reference to the peculiar "Friedreich psychosis" which has been described by several authors, among whom we may note Klein (1937).

The aim of the present study is to describe some cases of mental change associated with Friedreich's ataxia, and to draw attention to certain clinical features of these cases, in an attempt to advance our knowledge of these curious states.

\section{Material and Methods}

Twenty cases of Friedreich's ataxia were seen. Three of these were met at the Maudsley Hospital, to which they had been admitted on account of severe mental disturbance. Many were traced through the neurological clinics of various London teaching hospitals. Certain of them were found to have become chronic inmates of London County Council hospitals. In every case the diagnosis had originally been made by a neurologist of some distinction, and frequently the patients had been seen at various times by more than one such consultant. Each case was examined physically and mentally, special enquiry being made for disturbances of -thought, mood, and consciousness. Any history of fits in patients or relations was particularly sought. Various clinical tests of mental state were applied in each case, in addition to formal intelligence testing, the results of which have already been described (Davies, 1949). Electroencephalography was carried out in fifteen cases.

\section{Case Histories}

A few of the more interesting cases from the $\vec{O}$ standpoint of the present investigation are described briefly here.

Case 1.-This patient, a boy of 15 years, was admitted to the Maudsley Hospital on Dec. 12, 1946, complaining of unreality feelings, hypnagogic hallucinations, transient ${ }^{\circ}$ losses of consciousness, and irritability.

Reference to the family tree (Fig. 1) shows abortine $\omega$ forms of Friedreich's ataxia in II/2 and III/6. II/79 subject to recurrent attacks of depression, and III the patient's mother, committed suicide in a secogd depressive attack.

The patient was a normal child until the age of 3 years, when scoliosis, ataxia, and titubation of the heforo first appeared, leading to a diagnosis of Friedreicls sof ataxia. He was a happy but somewhat solitary chi@; devoted to his father and step-mother (who was also his maternal aunt). In July 1946 he started housebreaking, then absconded from home, and on return was stubborn and irritable. In November 1946 he put poison in his father's food, and bought a rope with which to hang his step-mother. Later that month he was found wandering in a state of confusion. About this time he became $\frac{0}{\mathbb{D}}$ strange at school where, following a retrosternal " feeling $\propto$ of excitement," he would suddenly bang desks and shout ${ }_{0}^{\overrightarrow{0}}$ for a few minutes, subsequently having no recollection 3 of this behaviour. On going to bed he would see visions?

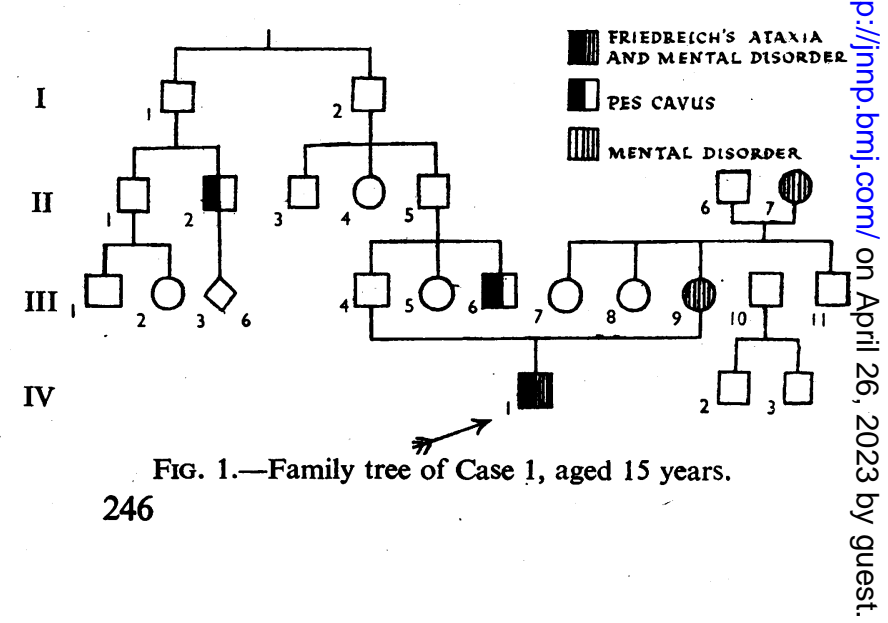




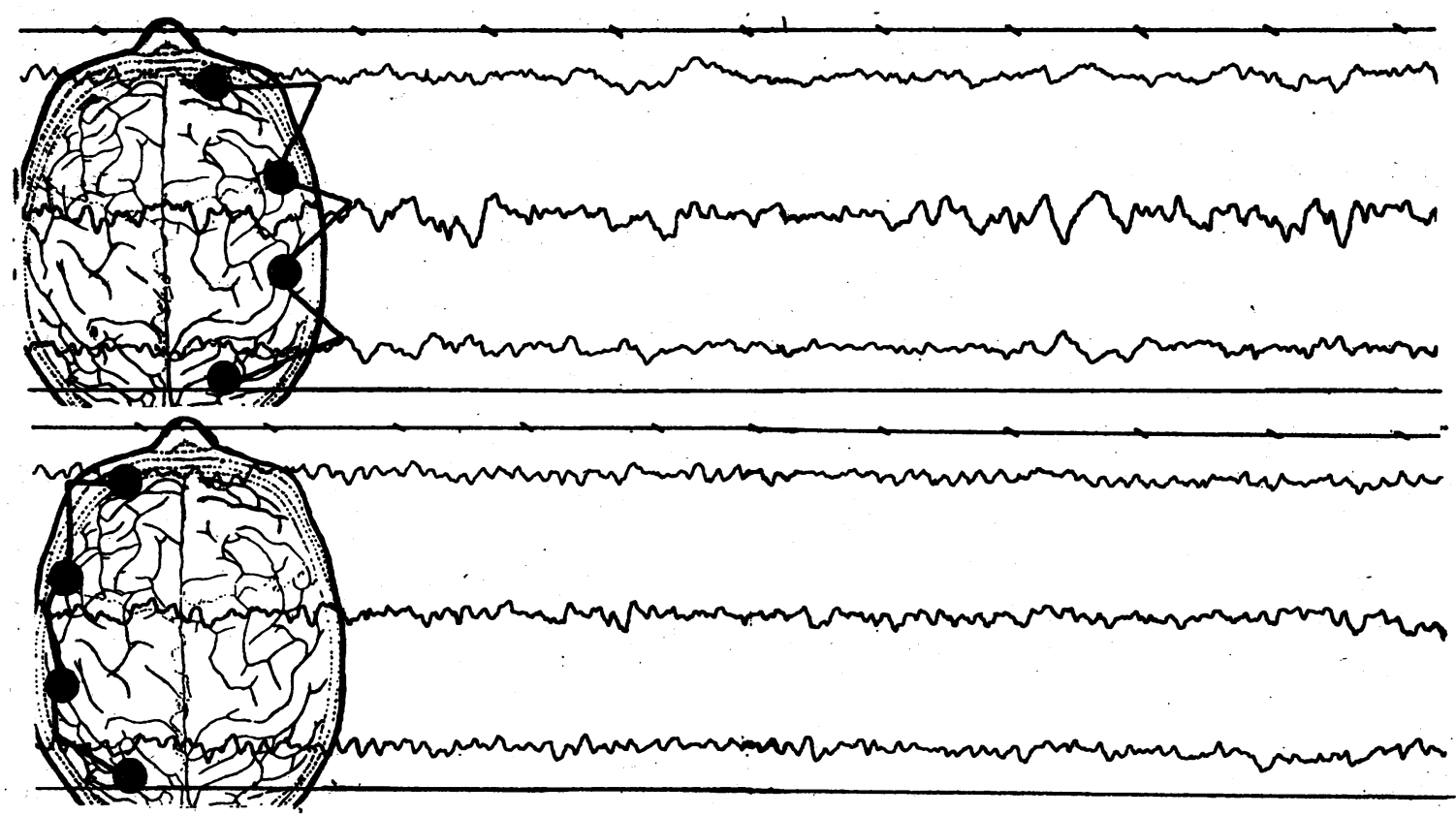

Fig. 2.-Electro-encephalogram of Case 1, showing slow frequencies in the right temporo-occipital area (upper tracing) as compared with the left temporo- occipital area (lower tracing).

before falling asleep. The first, a diminutive man in ruffles and buckled shoes would utter the word, "Transformation"; the second man, an archer, spoke the word, "Navardo."

On admission he was grossly ataxic, and showed, among other features, dysarthria, pes cavus, scoliosis, nystagmus, absent knee jerks, and extensor plantar responses. There was a soft apical systolic heart murmur, and the electrocardiogram revealed right axis deviation. Blood, cerebrospinal fluid, and perimetry revealed nothing abnormal. He was unhappy and tearful, expressed hatred of his father and step-mother, and said they were plotting against him : if sent back to them he would murder them. Attention, concentration, and orientation were unimpaired. Memory was good except for his fugues. Psychological testing revealed average intelligence and no evidence of deficit.

During his stay in hospital he remained paranoid and subject to sudden outbursts of rage. On at least one occasion fits with tōnic and clonic phases were observed. On Dec. 30, 1946, an electro-encephalogram (Fig. 2) was grossly abnormal, showing slow frequencies throughout but most prominently in the right temporo-occipital area. On March 22, 1947, he became suddenly euphoric, denied his hatred of his family, and consented to see them for the first time. This euphoria diminished towards the date of his discharge on April 30, 1947. He worked well as a laboratory technician until October 1947, when he had a fugue. He was re-admitted in November 1947, but in December 1947 he went home. He attacked his family, threw vitriol over a neighbour, and afterwards was certified.
Case 2.-A widow aged 21 years was admitted to the Maudsley Hospital on Dec. 21, 1946 because of fits. She was one of two siblings and four half-siblings, all healthy, but her mother had titubating head tremor, absent knee and ankle jerks, and extensor plantar responses.

The patient had been a healthy child and average scholar. She was a clerk until the age of 17 years, and then a shop assistant until she married at 20 years. A few months later her husband was killed in a road accident. There were no children of the marriage. She had been a cheerful woman until March 1945, when she had three major epileptic fits within three days. In the spring of 1946 she had been admitted to another hospital in status epilepticus. In August 1946 she became clumsy with her hands, stumbled often, and dysarthria began.

Her ataxia necessitated conveyance to hospital on a stretcher. She had among other signs dysarthria, nystagmus, absent knee and ankle jerks, extensor plantar responses, scoliosis, pes cavus, and wasting of the small muscles of the hands. There was no sphincter disturbance; blood and cerebrospinal fluid were normal. She was euphoric, often laughing oùt loud. She answered questions well and to the point. Orientation was good. Attention and concentration were unimpaired. Her intelligence seemed low, and formal testing gave a Wechsler I.Q. of 75. In view of her history this suggested deterioration.

During her stay in hospital her mood fluctuated considerably, between marked cheerfulness and bitter weeping. At times she was querulous and resentful. 
She was frequently drowsy, and had many major fits. The electro-encephalogram revealed-high voltage, frontal, paroxysmal delta activity, with slow rhythms in the right temporo-occipital area. On April 3, 1947, she went home, and she died a month later in status epilepticus. No autopsy could be performed.

Case 4.-A single woman aged 24 years was admitted to the Maudsley Hospital on May 3, 1946, complaining of depression. There was no history of mental or nervous disease in her parents or their families, but a brother (two years older than the patient) had Friedreich's ataxia and was investigated in this series. The patient had been a nervous child, shy and timid during her school years. At 14 she left school in the top standard, and in that year ataxia, pes cavus, scoliosis, and other evidence of Friedreich's ataxia were noted. She had never worked in consequence, and had become reduced to an invalid chair within a few years. A year before admission she began to be irritable, " could not be bothered with anything," and had " nothing to live for." When admitted she had the usual features of Friedreich's ataxia. At the psychiatric examination she was miserable. She answered questions slowly, and frequently was on the verge of tears. She described her mood as one of extreme unhappiness; there was self reproach and remorse. Orientation, memory, attention, and concentration were unimpaired. She seemed of average intelligence, and there was no clinical evidence of deterioration. The electro-encephalogram was within normal limits.

She improved with conservative treatment and occupational therapy, gained weight, became much more cheerful, and was enabled to return home.

Case 15. - A married man aged 28 years was traced through the London Hospital, where he had been an in patient at the age of 17 years with the diagnosis of " Friedreich's ataxia and schizophrenia." There was no nervous or mental trouble in the parents or their families. The patient was one of seven children. A younger sib had had chorea in childhood, and another younger sib had been epileptic before being killed in a road accident. The patient himself had been a normal child except for epileptic fits between the ages of 2 and 5 years. Scoliosis was first observed at the age of 10 years. He went to a secondary school at 11 years, was a good scholar, and left for an engineering job at the age of 14 . At the age of 17 years, 2 weeks after recovery from influenza, he suddenly became strange in his manner. He would gaze into space and seemed visually hallucinated. Then he would shout and swear at his parents. He was prevented from strangling his baby sister, became very restless, and secreted a razor. In hospital he was reported as showing the physical signs of Friedreich's ataxia and well-marked catatonia. He was transferred to a mental hospital, where he was described as being hallucinated. He heard voices calling him into the woods. He had ideas of reference, and sudden impulsive behaviour. He improved over a period of about six months, and was discharged recovered.

When seen in December 1946 he was employed as a bookkeeper. His physical state had undergone very little deterioration. There was no mental abnormality or intellectual deterioration.

\section{Discussion}

The case histories included here are of those patients with marked mental symptoms. For reasons of space it is not possible to give other case historigs where psychiatric phenomena were less evident, but reference to these, where they are helpful, will made. It is clear that a variety of mental disorders may be seen in Friedreich's ataxia, and the symptoryatology of these will be discussed.

The " Friedreich Psychosis." -Under this design? tion several authors, notably Klein (1937) and Bleuler and Walder (1946), have described patieniss showing schizophreniform illnesses. Case 1 afof Case 15 in our series are excellent examples of this group (although they show some atypical features such as the tendency to remit in Case 1, and the complete recovery in Case 15). Case 1 displayed very markedly the periodic outbursts of wild excite ment which have been described by nearfy all those who have studied these cases. Reference to Saquet's (1919) Case VI, Kalinowsky (1909\%, Lhermitte and others (1933), Trelles (1934), de Smet and others (1937) leaves one in no doubt that this furious excitement is a very characte istis feature of the behaviour of these patients. Previgisly there has been no record of the electro-encepharisgrams of such patients, although the co-existene epilepsy with the Friedreich psychosis was noted. by Kroll and Terentjew (1914), Walter and Roese (1926), and Bielchowsky and others (1934). Careftil observation over a long period revealed the occuf rence of epileptic fits in our 15-year-old Case 1 akd the electro-encephalograph record (Fig. 2) is of gre interest, characterized as it is by a theta rhython which tends to remain unilateral and right-sided. This is the rarer abnormality which Hill (1944) found among the electro-encephalograph records $\mathrm{gf}_{\mathrm{f}}$ psychopaths, and he associated it with " the mowe dramatic and severe behaviour disorders." It wầs well shown in one of Hill's cases who had been charged with murder (it will be recalled here that our Case 1 made more than one attempt at murder

The genetic implications of the association between psychosis and Friedreich's ataxia hagie received notice, chiefly from de Smet and others (1937). It is noteworthy in our material that in the family tree of Case 1 (Fig. 1) there is strong evidence of mental instability on the maternal side of the family, and evidence of Friedreich's ataxia in formi fruste on the paternal side of the family. If anythiong can be concluded from this particular case it would favour a double inheritance of predisposition to physical and mental disorder, very similar to that 
claimed for their case by Birkmayer and Lenz (1939).

States of Clouded Consciousness.-Cases 1 and 2 in our series illustrated very well the occurrence of confusional periods, in this instance obviously associated with clinical epilepsy.and an abnormal electroencephalogram. It is worth recalling that in his original description of the disease which now bears his name Friedreich (1863) described periodic disturbance of consciousness associated with fits, though he called the condition " hysterical." The rarity of acute episodic disturbances of consciousness in association with Friedreich's ataxia has been commented on by Bleuler and Walder (1946), and it is significant that where such occurred in our series (Cases 1 and 2) there was associated major epilepsy.

Throughout our series there has been a noteworthy occurrence of epilepsy among patients or their siblings. Cases 1, 2, and 17 in our original series of twenty cases were subject to clinical fits and had abnormal electro-encephalograms. Case 15 had a history of epilepsy in childhood, and Case 12 had a brother who had died in a mental hospital where he had been described as an epileptic idiot. This association of epilepsy and Friedreich's ataxia has received notice in the past, but in this series, which includes some cases of Friedreich's ataxia with severe mental symptoms, the relatively high incidence of epilepsy cannot escape without comment.

In the occurrence of epilepsy with Friedreich's ataxia cardiac involvement should be mentioned. Pitt.(1886) first described the occurrence of cardiac disease in Friedreich's ataxia. Evans and Wright (1942) encountered a Stokes-Adams syndrome in one of these patients, and their electrocardiographic work, with the pathological studies of Russell (1946), have clearly established cardiac involvement. This is not, however, the basis of the epilepsy seen in our cases, for electrocardiograms in the epileptic patients revealed only the minor changes described by Evans and Wright, whereas Case 3 of our original series, who had an electrocardiogram showing inversion of the $\mathbf{T}$ wave in all leads and whose heart was considerably involved clinically, was not epileptic.

Depressive Illness. - The patient who suffered most evidently from depression was Case 4. Mood change, loss of weight, loss of appetite and sleep, with feelings of hopelessness were present. A reactive element clearly preponderated in the genesis of the state, and she responded well to general measures of treatment.

Electro-encephalograph Changes.-Of the fifteen cases examined in this way three (who had clinical epilepsy) had grossly abnormal rhythms. Three more cases had mildly abnormal rhythms, and nine cases were reported as being within normal limits. Among the six cases with various degrees of abnor- mality of rhythm this abnormality included temporal theta rhythm in five cases, and one record was of the rare frontal alpha. The series is too small to provide a basis for any far-reaching conclusions, but the persistence of theta rhythms may have some bearing on the excitement in the Friedreich psychosis to which attention has already been drawn.

Personality Patterns. - In a disease which becomes evident in early adolescence it is difficult to talk of changes in personality, and in chronic invalids from any cause it is easier to note the personality traits descriptively than to assign ætiologically the relative roles of factors which may be genetic, environmental, or specific to the illness. Certainly some unusual personalities were encountered among the patients seen. One of these, an intelligent woman aged 32 years, whose physical incapacity seemed only very slowly progressive, had undergone a process of violent religious conversion. She had thrown herself into evangelical and charitable work, and supported a preacher every Sunday at numerous open air meetings. Another patient had developed tremendous religious preoccupations under the influence of her mother to whom she was tied by physical incapacity. Yet another, bedridden in hospital for many years, had turned to popular psychology and mystical modes of expression.

Two of the patients showed physical and sexual immaturity with poor intelligence. One of these, a girl of 25 years, was diabetic and a petty thief. The occurrence of diabetes with Friedreich's ataxia has been noted by Schloss (1932) and Wichtl (1933) ; and Flatau (1908) has drawn attention to the medicolegal implications of delinquency in Friedreich's ataxia.

Although some patients showed extreme irritability, others, in contrast, showed a contentment and serenity upon which Hanhart (1923) has commented. Our Case 5, aged 27 years, affected a lordly disdain for his similarly affected sister (Case 4), whom he despised for her willingness to consult doctors. His self-satisfaction and complacency contrasted with his sister's equally evident dependency.

\section{Conclusions}

The clinical characteristics of mental change in those affected by Friedreich's ataxia have been used by Bleuler and Walder (1946) to support their view of the " psycho-organic syndrome." The evidence they quote there for observable cerebral damage in these cases is far from satisfactory, and is at variance with the negative findings of Spiller (1910), Wichtl (1933), Trelles (1934), and Hassin (1938). Sjögren's (1943) claim for a progressive dementia in Friedreich's ataxia, which Bleuler accepts, has been criticised 
elsewhere by Davies (1949). Nevertheless the similarity between these psychotic states and some epileptic psychoses is not denied, and the occurrence of epilepsy among our series has a bearing on this point.

There can be no "simple explanation" of the genesis of any psychosis. The psychosis of Friedreich's ataxia are no exception to this rule. The unit with which we deal is not just the individual, but the individual in his environment. Genetic and development factors must be taken into consideration, as well as the innumerable influences in childhood and in adult life which play a part in the integration of personality, some being incorporated into personality structures, and others providing the immediate factors to which such resilient personality must attune itself. To draw parallels betweep the psychosis of different types, as between the Friedreich psychosis and the epileptic psychoses, may be of value for diagnostic purposes but helps little towards any clearer understanding of the genesis of either. Allowing for the imponderable factors already referred to as causative agents, there is still the question of the form of the mental disorder to be considered. It may well be that this is to be accounted for by disturbances at levels where pathological demonstration is not possible but where reflected abnormality in the electro-encephalogram may be expected.

\section{Summary}

1. Some cases of mental disturbances in association with Friedreich's ataxia have been described. These comprise the rare form of great severity, characterized by paranoid feelings and outbursts of excitement, in addition to depressive and confusional stạtes.

2. The association with epilepsy is discussed, and abnormal electro-encephalogram findings are recorded. It is suggested that these may help to account for some features of the symptomatology in certain of these cases.
My thanks are due to Dr. Denis Hill for the electro- $Z$ encephalograms, and to the late Dr. E. Guttman for his constant advice and criticism.

I am indebted to the following for permission to make use of their cases : Dr. Russell Brain, Dr. W. J. Christie, Dr. William Evans, Mr. Ivor Lewis, Dr. S. A. MacKeith, Dr. Martin Roth (Case 2), and the Medical Superinten-(s) dents of St. Benedict's and St. John's Hospitals, London.

Part of the expenses were defrayed by the Maudsley Bequest.

\section{REFERENCES}

Bielchowsky, M., Bouman, L., and Smitt, W. G. S. (1934).

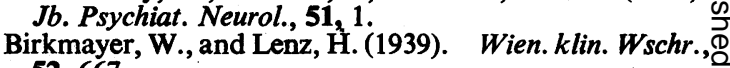
52, 667.

Bleuler, M., and Walder, H. (1946). Schweiz. Arch.œ

Neurol. Psychiat., 58, 44.
Davies, D. L. (1949). J. Neurol. Neurosurg. Psychiat.,,$\vec{\circ}$ n.s., $12,34$.

Evans, W., and Wright, G. (1942). Brit. Heart J., 4, 91 .

Flatau, G.(1908). Dtsch. Z. Nervenheilk., 35, 461.

Friedreich; N. (1863). Virchow's Arch., 26, 391.

Hanhart, E. (1923). Schweiz. Arch. Neurol. Psychiat., 13,297 . .

Hassin, G. B. (1938). Arch. Neurol. Psychiat., Chicage; $\tilde{\omega}$ 39, 116.

Hill, D. (1944). Proc. R. Soc. Med., 37, 317.

Kalinowsky, L. (1929). Dtsch.Z. Nervenheilk., 108, 28. Klein, D. (1937). Schweiz. Arch. Neurol. Psychiat., 39 and 320 .
39,

Kroll, M., and Terentjew, A. (1914). Z. ges. Neuripl. Psychiat., 26, 352.

Lhermitte, J., Mollaret, P., and Trelles, J. (1933). neurol., 40, 795.

Peter, C. (1927). Z. ges. Neurol. Psychiat., 108, 543

Pitt, G. N. (1886). Guy's Hosp. Rep., 44, 369.

Russell, D. S. (1946). J. Path. Bact., 58, 739.

Saquet, R. (1919). Thèse de Paris.

Schloss, J. (1932). Dtsch. Z. Nervenheilk, 125, 201.

Spiller, W. G. (1910). J. nerv. ment. Dis., 37, 411.

Sjögren, T. (1943). Acta. Psychiat. Kbh., Supp. 27.

de Smet, E., de Wulf, A., Dyckmans, and Van Bogaert, L (1937). J. belge Neurol., 37, 155 .

Trelles, J. O. (1934). Ann. Med.-psychol., 92, ii, 760.

Walter, F. K., and Roese, H. F. (1926.) Dtsch. $Z$. Nervenheilk., 92, 8.

Wichtl, O. (1933). Arb. Neurol. Inst. Univ. Wien., 35,

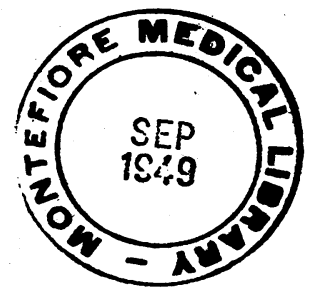

